median TAHS, AAHS and THS reduced from 10 to $2.5,12$ to 6 and 21 to 10 , respectively (Figure 1).

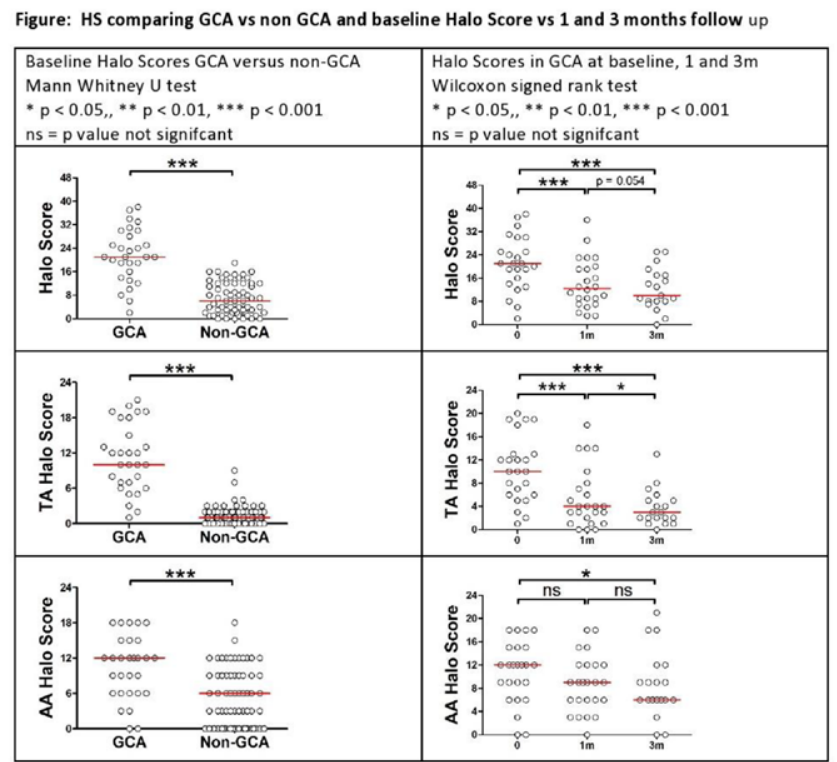

AA, Axillary artery; GCA, Giant cell arteritis; TA, Temporal artery

Conclusion: Along with SPTPS, Halo Score successfully discriminates GCA from non GCA mimics. HS is effective in showing 3-month response and may be a useful marker to monitor GCA disease activity.

REFERENCES:

[1] Laskou F et al. A probability score to aid the diagnosis of suspected giant cell arteritis. Clin Exp Rheumatol. 2019

[2] Sebastian A et al. Probability-based algorithm using ultrasound and additional tests for suspected GCA in a fast-track clinic. RMD Open. 2020

[3] Sebastian A et al. Halo score (temporal artery, its branches and axillary artery) as a diagnostic, prognostic and disease monitoring tool for Giant Cell Arteritis (GCA). BMC Rheumatol. 2020

Disclosure of Interests: Alwin Sebastian: None declared, Alessandro Tomelleri: None declared, Abdul Kayani: None declared, Mohammad Tariq: None declared, Diana Prieto-Peña: None declared, Sue Inness: None declared, Jo Jackson: None declared, Kornelis van der Geest Speakers bureau: Roche, Bhaskar Dasgupta Speakers bureau: Roche, GSK, BMS, Sanofi, Abbie, Grant/research support from: Roche

DOI: 10.1136/annrheumdis-2021-eular.1038

\section{POS0338 1 STEROID-SPARING EFFECT OF ANAKINRA IN GIANT- CELL ARTERITIS: A CASE SERIES WITH CLINICAL, BIOLOGICAL AND ICONOGRAPHIC LONG-TERM ASSESSMENTS}

S. Deshayes ${ }^{1}$, K. Ly ${ }^{2}$, V. Rieu ${ }^{3}$, G. Maigné ${ }^{1}$, N. M. Silva ${ }^{1}$, A. Manrique ${ }^{4}$, J. Monteil ${ }^{5}, \mathrm{H}$. De Boysson ${ }^{1}$, A. Aouba ${ }^{4}$ on behalf of the French Study Group for Large Vessel Vasculitis (GEFA). ${ }^{1} \mathrm{CHU}$ de Caen Normandie, Internal Medicine, Caen, France; ${ }^{2} \mathrm{CHU}$ Dupuytren, Internal Medicine, Limoges, France; ${ }^{3} \mathrm{CHU}$ Estaing, Internal Medicine, Clermont-Ferrand, France; ${ }^{4} \mathrm{CHU}$ de Caen Normandie, Nuclear Medicine, Caen, France; ${ }^{5} \mathrm{CHU}$ Dupuytren, Nuclear Medicine, Limoges, France

Background: The treatment of giant cell arteritis (GCA) relies on corticosteroids but is burdened by a high rate of relapses and adverse effects. Anti-interleukin- 6 treatments show a clear benefit with a significant steroid-sparing effect, but late relapses occur after treatment discontinuation. In addition to interleukin-6, interleukin-1 also appears to play a significant role in GCA pathophysiology.

Objectives: We report herein the efficacy of anakinra, an interleukin-1 receptor antagonist, in 6 GCA patients exhibiting corticosteroid dependence or resistance, specifically analyzing the outcome of aortitis in 4 of them, and including the long-term follow-up of 2 previously described patients (1).

Methods: This retrospective study analyzed the cases of all GCA patients treated with anakinra from the French Study Group for Large Vessel Vasculitis.

Patients had to satisfy the following two criteria to be enrolled in this retrospective study. First, their diagnosis of GCA should be based on the fulfillment of at least 3 criteria of the American College of Rheumatology (ACR) for GCA or on the satisfaction of 2 of these criteria along with the demonstration of LVI on imaging. Second, patients should have received anakinra because of corticosteroid dependence or resistance.
Corticosteroid dependence was defined as $\geq 2$ relapses or the combination of 2 of the following criteria: a daily dose of oral prednisone $>20 \mathrm{mg} /$ day (or $0.3 \mathrm{mg} /$ $\mathrm{kg}$ ) at 6 months; a daily dose of oral prednisone $>10 \mathrm{mg} /$ day (or $0.2 \mathrm{mg} / \mathrm{kg}$ ) at 12 months; and/or a treatment maintained $>24$ months because of a relapsing disease course. Corticosteroid resistance was defined as persistent increased inflammatory parameters at month 3 despite a steroid dosage over $0.5 \mathrm{mg} / \mathrm{kg}$ Results: After a median duration of anakinra therapy of 19 [18-32] months, all 6 patients exhibited complete clinical and biological remission. Among the 4 patients with large-vessel involvement, 2 had a disappearance of aortitis under anakinra, and 2 showed a decrease in vascular uptake. After a median follow-up of 56 [48-63] months, corticosteroids were discontinued in 4 patients, and corticosteroid dosage could be decreased to $5 \mathrm{mg} /$ day in 2 patients. One patient relapsed 13 months after anakinra introduction in the context of increasing the daily anakinra injection interval to every 48 hours. Three patients experienced transient injection-site reactions, and 1 patient had pneumonia.

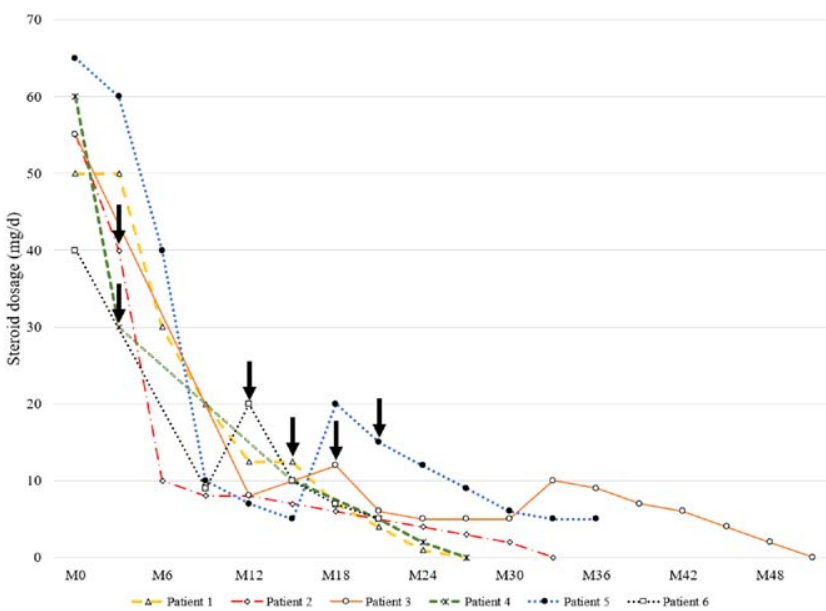

Figure 1. Steroid dosages before and after the introduction of anakinra in 6 patients with giant-cell arteritis and corticosteroid dependence or resistance. The black arrow indicates the time of anakinra introduction.

Conclusion: In this short series, anakinra appears to be an efficient and safe steroid-sparing agent in refractory GCA, with a possible beneficial effect on large-vessel involvement.

\section{REFERENCES:}

[1] Ly K-H, Stirnemann J, Liozon E, Michel M, Fain O, Fauchais A-L. Interleukinblockade in refractory giant cell arteritis. Joint Bone Spine 2014;81:76-8.

Disclosure of Interests: Samuel Deshayes: None declared, Kim LY: None declared, Virginie Rieu: None declared, Gwénola Maigné: None declared, Nicolas Martin Silva: None declared, Alain Manrique: None declared, Jacques Monteil: None declared, Hubert de Boysson Speakers bureau: Roche-Chugai, Grant/ research support from: Roche-Chugai, Achille Aouba Grant/research support from: SOBI

DOI: 10.1136/annrheumdis-2021-eular.1623

\section{POS0339 \\ PREDICTORS OF DEATH IN PATIENTS DIAGNOSED WITH GIANT CELL ARTERITIS IN WESTERN NORWAY 1972-2012}

L. K. Brekke ${ }^{1}$, B. T. Svanes Fevang ${ }^{2}$, J. Assmus ${ }^{3} .{ }^{1}$ Hospital for Rheumatic Diseases, Rheumatology, Haugesund, Norway; ${ }^{2}$ Haukeland University Hospital, Rheumatology, Bergen, Norway; ${ }^{3}$ Haukeland University Hospital, Centre for Clinical Research, Bergen, Norway

Background: Giant cell arteritis (GCA) is the most common systemic vasculitis in adults, and the number of incident cases worldwide is projected to increase [1]. Evidence as to whether or not GCA confers a mortality risk is conflicting, and many studies have been limited by inadequate or lacking adjustment for confounders.

Objectives: To investigate possible predictors of death in a large and well char acterized Norwegian cohort of GCA-patients.

Methods: This is a hospital-based retrospective cohort study including patients diagnosed with GCA during 1972-2012. Patients were identified through computerized hospital records using the International Classification of Diseases coding system. Clinical information was extracted from patients' medical journals. Further details about the inclusion process have been published previously [2] Information on time of death was obtained from the Norwegian Cause of Death Registry. We investigated predicting factors using Cox regression. Selected variables were first analyzed in univariate and block regression models (block 1 : 